\title{
Clinical characteristics and electroencephalographic findings of first seizure episode in children
}

\author{
*Ramesh Y Bhat ${ }^{1}$, Atul Thobbi ${ }^{1}$, Pushpa Kini ${ }^{1}$, Shrikiran Hebbar ${ }^{1}$ \\ Sri Lanka Journal of Child Health, 2022; 51(1): 39-45 \\ DOI: http://dx.doi.org/10.4038/sljch.v51i1.9990
}

\begin{abstract}
Introduction: Eyewitness and review of recorded video help in identifying seizure semiology in children. Electroencephalography (EEG) further helps to establish the diagnosis, ascertain the site of seizure origin, and to classify the epilepsy.
\end{abstract}

Objectives: To study the clinical seizure types and associated EEG findings.

Method: Children aged one month to 18 years with first seizure were enrolled prospectively. The detailed history, seizure type, examination findings and EEG characteristics, including wave pattern, spike-wave complexes, background, rhythm and epileptiform discharges, were studied.

Results: Among 475 children with seizures; generalized seizures constituted 237 (49.9\%), focal seizures $131(27.6 \%)$, generalized status $31(6.5 \%)$, focal status $6(1.3 \%)$, epileptic encephalopathy 28 $(5.9 \%)$ and epileptic syndromes $7(1.5 \%)$. Seizures of generalized tonic-clonic type were observed in $134(28.2 \%)$, absence in $21(4.4 \%)$, atonic in 9 $(1.8 \%)$ and myoclonic in $42(8.8 \%)$. Focal seizures (FS) with impaired awareness (IAW), FS with awareness $(\mathrm{AW})$ and bilateral tonic-clonic were 37 $(7.8 \%), 30(6.3 \%)$ and $58(12.2 \%)$ respectively. EEG was abnormal in 394 (82.9\%) children; 121 (30.7\%) had epileptiform sharp/spike waves, 89 (22.5\%) had slow waves, 47 (11.9\%) had tri-phasic waves, 70 $(17.7 \%)$ had poly-spike complexes, 63 (15.9\%) had an abnormal background with slow-wave activity and $3(0.7 \%)$ had hypsarrhythmia. All atonic and

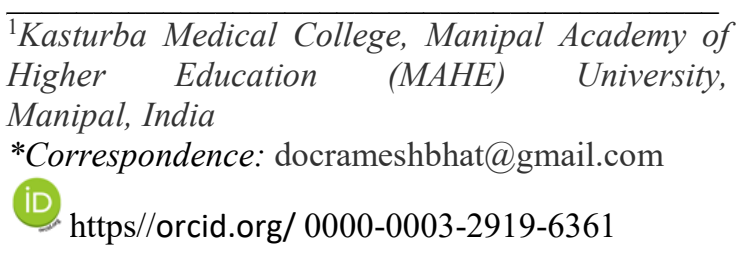

(Received on 25 December 2020: Accepted after revision on 19 February 2021)

The authors declare that there are no conflicts of interest

Personal funding was used for the project.

Open Access Article published under the Creative

Commons Attribution CC-BY (c) (i) License myoclonic seizures, generalized status, epileptic syndromes and $71.4 \%$ of absence seizures had associated generalized epileptic abnormalities on EEG. Percentage of children having associated EEG abnormalities was higher among focal seizures $(74.8 \%)$ than generalized seizures $(60.3 \%)$.

Conclusions: EEG evaluation provided additional information in a large number of children with seizures. Focal seizures had higher associated EEG changes than generalized seizures.

(Key words: Children, Electroencephalography, Seizures, Status epilepticus)

\section{Introduction}

A seizure can be the presenting feature of a grave medical disorder or subsequent epilepsy ${ }^{1,2}$. Around $4-10 \%$ of children have at least one seizure in the first 16 years of life $^{2,3}$. As medical personnel frequently do not witness the initial seizure, eyewitness accounts and reviews of recorded videos help in the evaluation of seizures. Family history of epilepsy, developmental history and a thorough general and nervous system examination further help to identify common epilepsy syndromes. Electroencephalography (EEG) aids in establishing the diagnosis of epilepsy, distinguishing epileptic seizures from non-epileptic events, determining the site of seizure origin and in classifying epilepsy and epilepsy syndromes ${ }^{2-7}$. Comparative studies of EEG with clinical data showed that the EEG can predict the prognosis and course of the uncontrolled seizures $^{4,5}$. As EEG is the best predictor for seizure recurrence and prognosis, identifying the EEG changes associated with first seizure in children become important.

\section{Objectives}

To study the clinical types of seizures in children and associated EEG changes.

\section{Method}

This prospective observational study was carried out between November 2017 and June 2019 on children admitted in the department of paediatrics at a tertiary teaching hospital. A pre-designed proforma was used to obtain a detailed history, seizure type, clinical examination findings and EEG characteristics. Children aged from 1 month to 18 years, admitted with first seizure episode, in which 
EEG was obtained, were enrolled. Neonates with seizures, febrile seizures, follow up cases and breakthrough seizures were excluded. Clinical description of the seizure was based on eyewitness account by parents, review of the video recording on mobile phones or witnessing of the event at the hospital by the medical team.

EEG was obtained in the post-ictal phase, after 24 hours, using a 26 lead international electrode placement, which comprised two electrodes for ECG, a pair of electrodes for EMG and remaining 22 leads on the scalp. Neurofax EEG machine, Nihon Kohden, Japan was used for EEG. In each case, three minute photic stimulation followed by three minute hyperventilation (in children older than two years) was obtained. The standard gel was used for recording. The machine sensitivity was 7 microvolt and the frequency used was $70 \mathrm{~Hz}$. Sleep deprivation of the patients was carried out to get the sleep EEG without the use of sedatives. EEG was recorded for 30 minutes in each case. The EEG was not repeated and continuous EEG recording was not used in this analysis.

The EEG was recorded by a trained EEG technician and read by a neurologist. The neurologist was blinded for clinical details and had a dedicated time slot to study EEG characteristics. Neurologist was not involved in patient care. Two neurologists were involved and controversies, if any, resolved by discussion. Each EEG record was analysed for background, rhythm, symmetry, and wave pattern. Entire record was reviewed for slow waves, spikes, sharp waves, spike-wave complexes, artefacts and physiological waves. Distribution of any abnormal rhythm and epileptiform discharges was recorded. Finally, each record was classified as normal or abnormal. Abnormal records were further classified as focal or generalized epilepsy, epilepsy syndromes or encephalopathies. Final diagnosis after EEG evaluation was correlated with clinical evaluation.

Ethical issues: Approval was obtained from the Institutional Ethics Committee of Kasturba Medical College, Manipal Academy of Higher Education University, Manipal, India (IEC NO-929/2017). Written informed consent was obtained from parents and assent, where possible, from the children.

Statistical analysis: Data were analysed using SPSS version 21. The results were summarized as frequencies and mean values. Chi-square test was used for clinical and EEG association.

\section{Results}

A total of 648 children with seizures were admitted during the study period (Figure 1).

Follow up cases and breakthrough seizures were observed in 141 children, and febrile seizures in 32 children; they were excluded. Finally, 475 children were analysed. Children in the age group of five years to ten years constituted $30.3 \%$ of the study population (Table1). The overall male: female ratio was $1.4: 1$.

Total number of children in the age group of one month to 18 years admitted in the Department of Paediatrics with seizures in whom EEG was obtained $=648$

Children included in the final analysis $=475$

Figure 1: Study flow chart 
Table 1

Demographic characteristics of the children

\begin{tabular}{|c|c|}
\hline Variable & n (\%) \\
\hline Age & \\
\hline 1 month -1 year & $114(24.0)$ \\
\hline $1-5$ years & $99(20.8)$ \\
\hline $5-10$ years & $144(30.3)$ \\
\hline $10-15$ years & $96(20.2)$ \\
\hline $15-18$ years & $22(04.6)$ \\
\hline Gender & \\
\hline Male & $271(58.7)$ \\
\hline Female & $204(41.3)$ \\
\hline
\end{tabular}

Figure 2 shows the clinical seizure types.
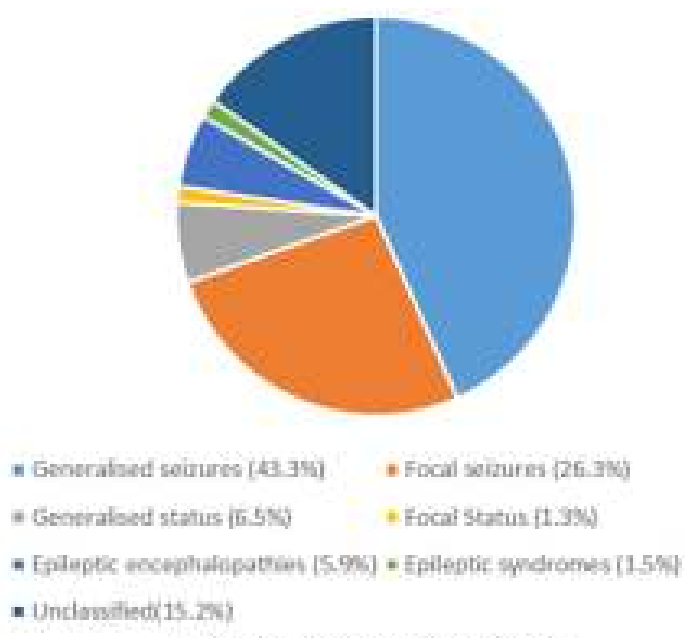

Figure 2: Cinical seizune types

Table 2 shows the distribution of seizure types.

Table 2: Distribution of seizure types $(n=475)$

\begin{tabular}{|l|c|}
\hline \multicolumn{1}{|c|}{ Variable } & n (\%) \\
\hline Generalised & $134(28.2)$ \\
Tonic-clonic & $21(04.4)$ \\
Absence & $09(01.9)$ \\
Atonic & $42(08.8)$ \\
Myoclonic & \\
\hline Focal & $37(07.8)$ \\
Focal with impaired awareness & $30(06.3)$ \\
Focal with awareness & $58(12.2)$ \\
Focal to bilateral tonic-clonic & $31(06.5)$ \\
\hline Generalised status & $06(01.3)$ \\
\hline Focal status & $28(05.9)$ \\
\hline Epileptic encephalopathies & \\
\hline Epileptic syndromes & $05(01.1)$ \\
West syndrome & $01(0.2)$ \\
Benign rolandic epilepsy & $01(0.2)$ \\
Dravet syndrome & $72(15.2)$ \\
\hline Unclassified &
\end{tabular}

In this study $237(49.9 \%)$ children had generalized seizures, $131(27.6 \%)$ had focal seizures and 72
(15.2) had unclassified seizures. Thirty seven had status epilepticus (31 had generalized status, 6 had focal status) and 28 children had epileptic encephalopathy. The most common type of seizure was a generalized tonic-clonic seizure (GTCS) (43.4\%) followed by focal seizures $(27.6 \%)$ (Table 2).

About $8.8 \%$ children had a past history of febrile seizures. Significant birth history and developmental delay were present respectively in $18.1 \%$ and $19.7 \%$ of the study population. Significant birth history included hypoxic ischaemic encephalopathy (HIE) stage 2 , transient metabolic abnormality with seizure that did not require anticonvulsant at discharge and hypoglycaemia which resolved within a short period of time. History of seizures in the family, neurocutaneous markers, microcephaly and neurological deficits were found in $15.6 \%, 19.5 \%$, $14.1 \%$ and $16.4 \%$ of the study population respectively. There was no significant difference in the presence of neurocutaneous markers between different types of seizure groups.

EEG changes were observed in 394 (82.9\%) children whilst the EEG was normal in 81 (17.1\%) children. Table 3 shows the distribution of EEG findings.

Table 3: Distribution of EEG findings $(n=475)$

\begin{tabular}{|l|c|}
\hline \multicolumn{1}{|c|}{ EEG finding } & n (\%) \\
\hline Normal & $81(17.1)$ \\
\hline Epileptiform sharp/spike waves & $121(30.7)$ \\
\hline Slow waves & $89(22.5)$ \\
\hline Triphasic waves & $47(11.9)$ \\
\hline Polyspikes/spike complex waves & $70(17.7)$ \\
\hline $\begin{array}{l}\text { Abnormal background with slow } \\
\text { wave complexes/activity }\end{array}$ & $63(15.9)$ \\
\hline Bilateral centro-temporal spikes & $01(0.2)$ \\
\hline Hypsarrhythmia & $03(0.7)$ \\
\hline
\end{tabular}

Among the 394 children with EEG changes, 83 (21.1\%) had focal EEG changes and 311 (78.9\%) had generalized EEG changes. The epileptiform sharp or with spike waves were the most common findings. In children with focal seizures, EEG showed predominantly slowing of waves or spike waves in specific unilateral leads. The EEG in children with epileptic encephalopathy showed slow-wave complexes. In a child with Benign Rolandic epilepsy, EEG showed classical bilateral centro-temporal spikes. EEG changes were significantly more associated with focal seizures than generalized seizures.

Table 4 shows the clinical seizure type and associated EEG findings in generalised and focal seizures. 
Table 4: Clinical seizure type and associated EEG findings in generalized and focal seizures

\begin{tabular}{|l|c|c|c|}
\hline \multirow{2}{*}{ Clinical type } & \multicolumn{3}{c|}{ Electroencephalographic (EEG) changes } \\
\cline { 2 - 4 } & $\begin{array}{c}\text { Normal } \\
\mathbf{n}(\%)\end{array}$ & $\begin{array}{c}\text { Generalised epileptic changes } \\
\text { n (\%) }\end{array}$ & $\begin{array}{c}\text { Focal epileptic changes } \\
\text { n (\%) }\end{array}$ \\
\hline Generalised seizures & & & $20(14.9)$ \\
Tonic clonic (n=134) & $34(25.4)$ & $80(59.7)$ & 0 \\
Absence (n=21) & $06(28.6)$ & $15(71.4)$ & 0 \\
Atonic (n=9) & 0 & $09(100.0)$ & 0 \\
Myoclonic (n=42) & 0 & $42(100.0)$ & $22(51.2)$ \\
\hline Focal seizures (FS) & & & $15(50.0)$ \\
FS with IAW (n=43) & $09(20.9)$ & $12(27.9)$ & $16(27.6)$ \\
FS with AW (n=30) & $06(20.0)$ & $09(30.0)$ & \\
FS to bilateral tonic-clonic (n=58) & $12(20.7)$ & $30(51.7)$ & \\
\hline
\end{tabular}

All children with atonic and myoclonic seizures had generalized epileptic changes in their EEG. In the case of absence seizures $71.4 \%$ of children had generalized EEG changes. Children with GTCS had generalized epileptic changes as well as focal changes in EEG. About $50 \%$ of children with focal seizures had focal epileptic changes in their EEG (Table 4).

All children with status epilepticus had associated EEG changes. The generalized epileptic changes were observed in epileptic encephalopathy, West syndrome, Dravet syndrome and Benign Rolandic Epilepsy. Among 72 children with unclassified seizures, 13 (18.3\%) had normal EEG, 48 (67.6\%) had generalized epileptic changes and $10(14 \%)$ had focal epileptic changes. A higher percentage of focal seizures $(74.8 \%, 98 / 131)$ had associated EEG changes compared to generalized seizures $(60.3 \%$, $143 / 237)$. The odds of having abnormal EEG in focal seizures was 1.9 times $(95 \%$ confidence interval 1.2-3.1) higher than those in children having generalized seizures. This association was statistically significant $(p=0.005 ; p<0.01)$.

\section{Discussion}

We studied 475 children with seizures. This is one of the largest studies of seizures in children from the region. Generalized seizures constituted 237 (49.9\%), focal seizures were 131 (27.6\%), generalized status epilepticus were $31(6.5 \%)$, focal status was $6(1.2 \%)$, epileptic encephalopathy were $28(5.8 \%)$ and epileptic syndromes were 7 and others were $7(1.4 \%)$. Generalized tonic-clonic seizures constituted 132 (27.7\%). Abnormal EEG changes were observed in $394(82.8 \%)$. The percentage of children having associated EEG change was higher among focal seizures (74.8\%) compared to those having generalized seizures $(60.3 \%)$.

Seizures in children cause a significant proportion of emergency ward visits, morbidity and mortality ${ }^{8-10}$. There was male preponderance. Similar male preponderance was observed by Haimanot $\mathrm{R}$, et $a l^{11}$ earlier. In contrast, female preponderance was observed in a study by Gallito et al ${ }^{12}$. GTCS was the commonest seizure type in children in the present study. In a study by Shinnar S, et al ${ }^{13}$ with a sample size of 613 , the most common seizure observed was GTCS (42\%) followed by focal seizure with secondary generalisation (23\%). Dwivedi $\mathrm{R}$, et $a l^{14}$ reported that $66.3 \%$ had generalized seizures and $33.6 \%$ had partial seizures in their study involving 98 children. GTCS were the most common type $(71.2 \%)$ in a study from China comprising of 319 children ${ }^{9}$.

The aetiology of the seizure is the most important factor that enables us to predict the recurrence risk after a first unprovoked seizure ${ }^{10}$. We observed that a significant birth history was present in $18.1 \%$ of children. Shinnar S, et $a l^{13}$ with a sample size of 613 , found abnormal birth history in $21 \%$ of the total study population. Baheti $\mathrm{R}$, et $a l^{15}$ found abnormal birth history in $19 \%$. In the present study, $19.7 \%$ of children had global developmental delay, $14.1 \%$ had microcephaly and $19.5 \%$ had neurocutaneous markers. Shinnar $\mathrm{S}$, et $a l^{13}$ reported neurocutaneous markers in $11 \%$ of their study population. We found about $16.4 \%$ of the children had neurological deficits on examination. There was a significant difference in the presence of neurological signs in focal seizure groups. Jageer $\mathrm{H}$, et $a l^{16}$ observed neurological deficits in $21 \%$ of patients in their study on partial seizures. Family history of seizure was observed in $15.6 \%$ in the present study. Total $13.2 \%$ of children having a family history of seizure was reported by Dwivedi $\mathrm{R}$, et $a l^{14}$. Intracranial infection, perinatal asphyxia and head trauma are major contributors to symptomatic epilepsy in Africa $^{4,17}$.

EEG is the most important investigation in the diagnosis of seizure and epilepsy. EEG and aetiology are the best predictors for seizure recurrence and prognosis. The parents of children having the first seizure always question whether such a seizure will recur or not. In this scenario, EEG changes associated with seizure become important. We found associated EEG changes in 394 (82.8\%) children with the first seizure. A much higher yield of EEG abnormalities, 94\% in a cohort of 329 children was reported by Lagunju IA, et $a l^{5}$. A $72 \%$ 
yield of EEG was found in a population-based study in Rochester, Minnesota by Baldin E, et $a l^{18}$. In the present study, the major EEG findings included 121 (30.7\%) epileptiform sharp/spike waves, 89 (22.5\%) slow waves, 47 (11.9\%) triphasic waves, 70 (17.7\%) polyspike complexes and 59 (14.9\%) abnormal background with slow-wave activity. Similar observations were reported by Lagunju IA, et $a l^{5}$. It is estimated that the recurrence risk in the first unprovoked seizure in children was significantly less in those with normal EEG (25\%) in comparison with those having abnormal EEGs $(54 \%)^{19}$. Although, whether EEG has to be included in counseling parents of children with first seizure is debatable, an abnormal EEG increases the risk of recurrence nearly two fold.

The percentage of children having EEG abnormalities was higher among focal seizures (74.8\%) compared to those having generalized seizures $(60.3 \%)$. This observation agrees with those reported by Shinnar $\mathrm{S}$, et $a l^{13}$. In their study, EEG abnormalities were observed in $42 \%$ of children, $56 \%$ with partial seizure and $35 \%$ with generalized seizure and the difference was statistically significant. In contrast, Baheti $\mathrm{R}$, et $a l^{15}$ reported that $77 \%$ children had abnormal EEGs in the generalized seizure group and $73 \%$ had abnormal EEGs in the partial seizure group. Radhakrishna $\mathrm{K}$, et $a l^{20}$ found EEG abnormalities in $83.6 \%$ of children and the abnormalities were generalized in $74 \%$ children. Betting LE, et $a l^{21}$, on the other hand, reported that the first EEG was normal in $45 \%$, only $33 \%$ having typical abnormalities among idiopathic generalized epilepsy patients. They further opined that treatment should be based on clinical history and not on a typical abnormal EEG pattern. EEG findings are also useful in prognosticating in children with newly diagnosed epilepsy and genetic generalized epilepsies ${ }^{3}$. All children with atonic and myoclonic seizures, generalized status epilepticus, epileptic syndromes had generalized epileptic abnormalities in the present study. The ictal generalized EEG abnormalities in a rare epileptic syndrome, benign myoclonic epilepsy, has been reported by Auvin S, et $a l^{22}$.

In the present study, there was a high incidence of EEG abnormalities in the focal seizure group. EEG is more likely to be informative in partial seizures than in generalized seizures ${ }^{15}$. A few children with generalized seizures had focal EEG abnormalities which may be due to focal onset seizure with rapid secondary generalization. Previously, focal abnormalities in $10 \%$ to $60 \%$ of generalized seizure patients were reported ${ }^{3}$. In the largest study to date, 98 of 962 patients with genetic generalized epilepsy had focal abnormalities ${ }^{23}$. The possible explanations and mechanisms for such findings is still under debate.
The strength of this study includes the largest number of children with seizures being enrolled. The seizure semiology is also more accurate as it was studied by a combination of parental witness, reviewing the video recordings and direct witness of the medical team. The parental witness and description was $100 \%$, video was available in $65 \%$ and seizure was witnessed by medical team in $60 \%$. An EEG was obtained in all enrolled children prospectively. Besides, a neurologist had dedicated time slot for EEG reporting, hence it was not compromised by busy patient care. The limitation of the study is that the effect of the treatment and follow up is not being studied. The study also did not include children having breakthrough seizures.

\section{Conclusions}

In this large study involving 475 children with seizures, generalized tonic-clonic seizures were the commonest clinical type. Overall, associated EEG changes were observed in $82.8 \%$ of children with seizures. All children with atonic and myoclonic seizures, generalized status epilepticus, epileptic syndromes and $71 \%$ of absence seizures had generalized epileptic abnormalities on EEG. The percentage of children having associated EEG changes was higher among focal seizures compared to those having generalized seizures. The EEG evaluation of childhood seizures added clinically useful information.

\section{References}

1. Hirtz D, Berg A, Bettis D, Camfield C, Camfield P, Crumrine $\mathrm{P}$, et al. Practice parameter: Treatment of the child with a first unprovoked seizure: report of the Quality Standards Subcommittee of the American Academy of Neurology and the Practice Committee of the Child Neurology Society. Neurology 2009; 60(2):166-75. https://doi.org/10.1212/01.WNL.0000033 622.27961.B6

PMid: 12552027

2. Berg AT, Berkovic SF, Brodie MJ, Buchhalter J, Cross JH, Boas WE, et al. Revised terminology and concepts for organization of seizures and epilepsies: report of the ILAE Commission on Classification and Terminology, Epilepsia 2015; 51(4): 676-85.

https://doi.org/10.1111/j.15281167.2010.0 2522.x

PMid: 20196795

3. Pack AM. EEG and clinical features of childhood absence predict clinical outcomes. Epilepsy Currents 2013; 13(6): 285-6. 
https://doi.org/10.5698/1535-7597-

13.6.285

PMid: 24348129 PMCid: PMC3854746

4. Szaflarski P. Can EEG predict outcomes in genetic generalized epilepsies? Clinical Neurophysiology 2014; 125: 215-6. https://doi.org/10.1016/j.clinph.2013.08.0 26

PMid: 24119445

5. Lagunju IA, Oyinlade AO, Atalabi OM, Ogbole G, Tedimola O, Famosaya A, et al. Electroencephalography as a tool for evidence-based diagnosis and improved outcomes in children with epilepsy in a resource-poor setting. Pan African Medical Journal 2015; 22: 328.

https://doi.org/10.11604/pamj.2015.22.328 .7065

PMid: 26977236 PMCid: PMC4769815

6. Murthy JM, Yangala R. Acute symptomatic seizures - incidence and etiological spectrum: a hospital-based study from south India. Seizure 2006; 8(3): 162-5.

https://doi.org/10.1053/seiz.1998.0251

PMid: 10356374

7. Ellenberg JH, Hirtz DG, Nelson KB. Age of onset of seizures in young children. Annals of Neurology 2010; 15(2): 127-34. https://doi.org/10.1002/ana.410150204 PMid: 6703653

8. Hauser WA, Beghi E. First seizure definitions and worldwide incidence and mortality. Epilepsia 2008; 49(Suppl1): 812.

https://doi.org/10.1111/j.15281167.2008.0 1443.x

PMid: 18184148

9. Chen CY, Chang YJ, Wu HP. New-onset seizures in paediatric emergency. Pediatrics and Neonatology 2010; 51:10311.

https://doi.org/10.1016/S18759572(10)600 $19-8$

10. Lizana JR, Garciá EC, Marina LLC, López MV, González MM, Hoyos AM. Seizure recurrence after a first unprovoked seizure in childhood: A prospective study. Epilepsia 2000; 41(8):1005-13. https://doi.org/10.1111/j.15281157.2000.t b00286.x

PMid: 10961628
11. Haimanot R, Lars Forsgren, Jan Ekstedt. Incidence of epilepsy in rural Central Ethiopia. Epilepsia 1997; 38(5): 541-6. https://doi.org/10.1111/j.15281157.1997.t b01138.x

PMid: 9184599

12. Gallitto G, Serra S, La Spina P, Postorino P, Lagan A, Tripodi F et al. Prevalence and characteristics of epilepsy in the Aeolian islands. Epilepsia 2005; 46(11): 1828-35. https://doi.org/10.1111/j.15281167.2005.0 0278.x

PMid:16302864

13. Shinnar S, Dell CO, Mitnick R, Berg AT, Moshe SL. Neuroimaging abnormalities in children with first unprovoked seizure. Epilepsy Research 2001; 43(3): 261-9. https://doi.org/10.1016/S09201211(00)002 06-0

14. Dwivedi R, Priya PS, Padmavathi P. A clinical study of new onset seizures in children aged 3-12 years. International Journal of Contemporary Pediatrics 2019; 6(2): 774-80.

https://doi.org/10.18203/23493291.ijcp201 90728

15. Baheti R, Gupta BD, Rajesh B. A study of $\mathrm{CT}$ and EEG findings in patients with generalized or partial seizures in Western Rajasthan. Journal of the Indian Academy of Clinical Medicine 2003; 4(1): 25-9.

16. Jageer H, Srinivasan S, Tiroumourougane SV, Mahadevan S, Elangovan S, Bhuvaneswari V. Cranial computed tomography in partial motor seizures. Indian Journal of Pediatrics 2004; 71(7): 641-4.

https://doi.org/10.1007/BF02724126 PMid: 15280614

17. Lagunju IA, Fatunde OJ, Takon I. Profile of childhood epilepsy in Nigeria. Journal of Pediatric Neurology 2009; 7(2): 135-40.

18. Baldin E, Hauser WA, Buchhalter JR, Hesdorffer DC, Ottman R. Yield if epileptiform electroencephalogram abnormalities in incident unprovoked seizures: a population-based study. Epilepsia 2014; 55(9): 1389-98. https://doi.org/10.1111/epi.12720 PMid: 25041095 PMCid: PMC4167205 
19. Shinnar S, Kang H, Berg AT, Goldensohn ES, Hauser WA, Moshé SL. EEG abnormalities in children with a first unprovoked seizure. Epilepsia 1994; 35: 471-6.

https://doi.org/10.1111/j.15281157.1994.t b02464.x

PMid: 8026390

20. Radhakrishnan K, Louis EKS, Johnson JA, McClelland RL, Westmoreland BF, Klass DW. Pattern-sensitive epilesy: Electroclinical characteristics, natural history and delineation of the epileptic syndrome. Epilepsia 2005; 46(1): 48-58. https://doi.org/10.1111/j.00139580.2005.2 6604.x

PMid: 15660768

21. Betting LE, Mory SB, Lopes-Cendes I, Li LM, Guerreiro MM, Guerreiro CAM, et al. EEG feature in idiopathic generalized epilepsy: Clues to diagnosis. Epilepsia 2006; 47(3): 523-8.

https://doi.org/10.1111/j.15281167.2006.0

0462.x

PMid: 16529616
22. Auvin S, Pandit F, De-Bellecize J, Badinand $\mathrm{N}$, Isnard $\mathrm{H}$, Motte $\mathrm{J}$, et al. Benign myoclonic epilepsy in infants: Electroclinical features and long-term follow-up of 34 patients. Epilepsia 2006; 47(2): 387-93.

https://doi.org/10.1111/j.15281167.2006.0 0433.x

PMid: 16499765

23. Nicolson A, Appleton RE, Chadwick DW, Smith DF. The relationship between treatment with valproate, lamotrigine, and topiramate and the prognosis of the idiopathic generalized epilepsies. Journal of Neurology, Neurosurgery and Psychiatry 2004; 75:75-9. 